\title{
EMLA cream induced bilateral corneal de-epithelization
}

\author{
Hong Nien Lee, MD, MMedOphth(D, Fazliana Ismail, MBBS (UM), MMedOphth (UM), \\ Visvaraja Subrayan, MBBS (UM), FRCS (UK), FRCOphth (UK), Fellowship (USA) \\ Department of Ophthalmology, Faculty of Medicine, University Malaya, Kuala Lumpur, Malaysia
}

EMLA cream is widely used in dermatological procedures and is frequently applied prior to cosmetic procedures. Limited restriction of use among the personnel who handle the patients or customers. The exposure of EMLA cream to the cornea can have profound effects; it poses the risks of eye infections, reduced vision, discomfort, and pain. The aim of this study was to increase the awareness of the side effects of EMLA cream application near the eyes. EMLA, being an alkaline cream, causes corneal injury rapidly; hence, precautions should be taken during its use. EMLA cream is easily accessible and widely used in the cosmetic industry. Its use near the eye region requires extra caution. Patients experiencing difficulty in opening the eyes and discomfort after application of EMLA cream near the eyes should not be ignored. It is important to avoid EMLA cream entering into the eyes during its applications on the eyelids. De-epithelized cornea is more prone to infection, subsequently resulting in scarring and permanent reduction in vision.

Keywords: cornea injuries; EMLA; eye infections; reduced vision

\section{Introduction}

EMLA cream 5\% (Aspen Medical Products, Malaysia) is a commonly used local anesthetic cream. It is indicated for use on the skin, genital mucosa, and leg ulcers. It contains two amidetype local anesthetics: lidocaine $2.5 \%$ (25 $\mathrm{mg} / \mathrm{g}$ ) and prilocaine $2.5 \%$ (25 mg/g) as an oil-in-water emulsion, with a pH of 9-9.2. It acts by temporarily numbing the skin and surrounding area. However, its exposure to the eyes can cause not only irritation but also corneal abrasion.

\section{Case report}

A 34-year-old woman presented with difficulty in opening both eyes, pain, tearing, and worsening of vision after undergoing eyeliner tattooing on both eyelids visited the emergency department. During the tattooing procedure, she noticed some irritation on the eyes when EMLA cream was applied to her eyelids; however, the remaining procedure was unremarkable. The sensation was tolerable at the beginning, and it gradually subsided. She kept her eyes closed for the entire time until the procedure was completed. Owing to the difficulty in opening her eyes, she rested at the tattoo center for approximately 1 hour. During that time, she started experiencing pain, tearing, and swelling of lids. Her ocular and medical histories were unremarkable. On examination, her right eye vision was $6 / 48 \mathrm{~m}$, pinhole $6 / 48 \mathrm{~m}$, and left eye vision was $6 / 36 \mathrm{~m}$, pinhole $6 / 24 \mathrm{~m}$. The post-irrigation $\mathrm{pH}$ of both the eyes was 7 . The upper eyelids were swollen, and the lashes were matted with mucosal slough and dark-pigmented particles covering the edges of the upper eyelids (Fig. 1, 2). Extraocular muscle motility was full. No relative afferent pupillary defect was noted. Areas of epithelial defect were noted on the lower halves of both the corneas with the sizes of $3.2 \mathrm{~mm} \times 4 \mathrm{~mm}$ (right eye) and $2.8 \mathrm{~mm} \times 3.8 \mathrm{~mm}$ (left eye)

Received June 30, 2020; Revised October 27, 2020; Accepted October 27, 2020

Corresponding author: Hong Nien Lee

E-mail: hongnien@ummc.edu.my

This is an Open Access article distributed under the terms of the Creative Commons Attribution Non-Commercial License (http://creativecommons.org/licenses/by-nc/4.0), which permits unrestricted non-commercial use, distribution, and reproduction in any medium, provided the original work is properly cited.

Copyright @ 2020 Korean Society of Korean Cosmetic Surgery and Medicine (KSKCS \& KCCS). 
(Fig. 3). The conjunctivae were injected. The anterior and posterior segments were unremarkable. She was administered an intensive lubrication, a topical combined preparation of antibiotic and steroid (TOBRADEX [Novartis Pharmaceuticals Ltd., London, UK] tobramycin $0.3 \%$, dexamethasone $0.1 \%$ ophthalmic suspension), and an oral analgesic. On subsequent review after 72 hours, the condition ameliorated and vision returned to $6 / 9 \mathrm{~m}$, pinhole $6 / 6 \mathrm{~m}$. Both the eyes exhibited a complete reso-

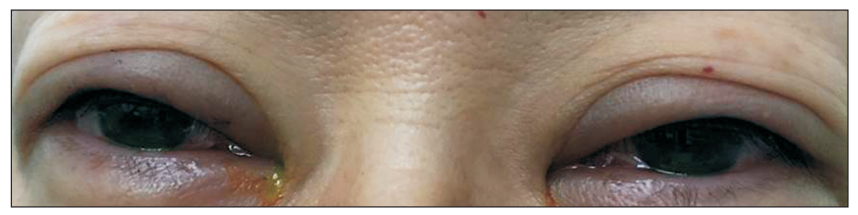

Fig. 1. Swelling of bilateral lids. lution of the epithelial defect with a poor ocular surface on the right eye (Fig. 3).

\section{Discussion}

Local anesthetics are known to disrupt the surface microvilli of epithelial cells, decrease mucous adherence, and shorten the tear breakup time in the cornea. The higher the concentration of the local anesthetic, the greater is its effect on the cornea. At $\geq 250 \mu \mathrm{g} / \mathrm{ml}$, it significantly impairs normal wound healing; particularly at $5,000 \mu \mathrm{g} / \mathrm{ml}(0.5 \%)$ and $10,000 \mu \mathrm{g} / \mathrm{ml}(1.0 \%)$, the stromal layer was reported to be swelled and transparency was lost [1].

Chemical burn injury to the cornea can be caused by acids or alkalis. Alkalis are lipophilic and can penetrate tissues faster
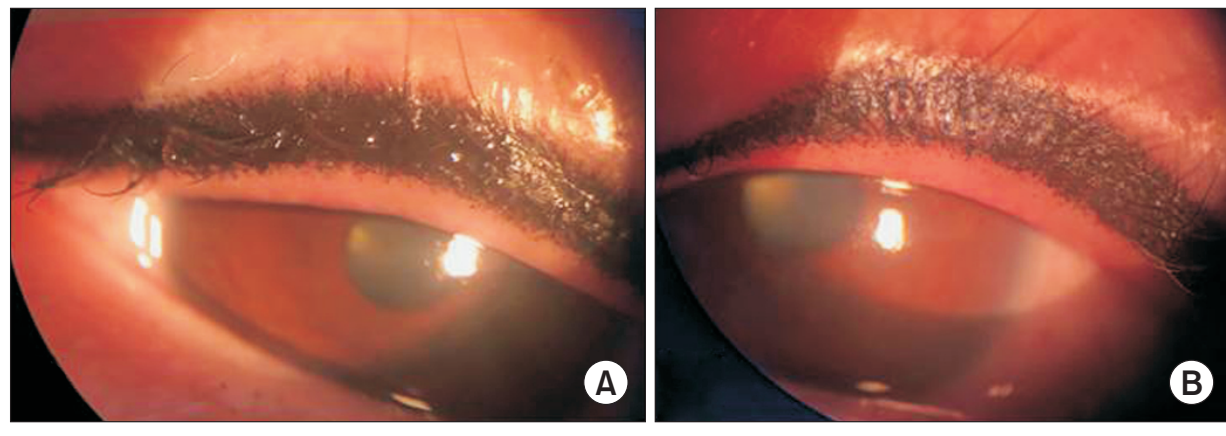

Fig. 2. Right eye (A) and left eye (B) with the fresh eyeliner tattoo. Epidermal burns were noted on the right upper lid.
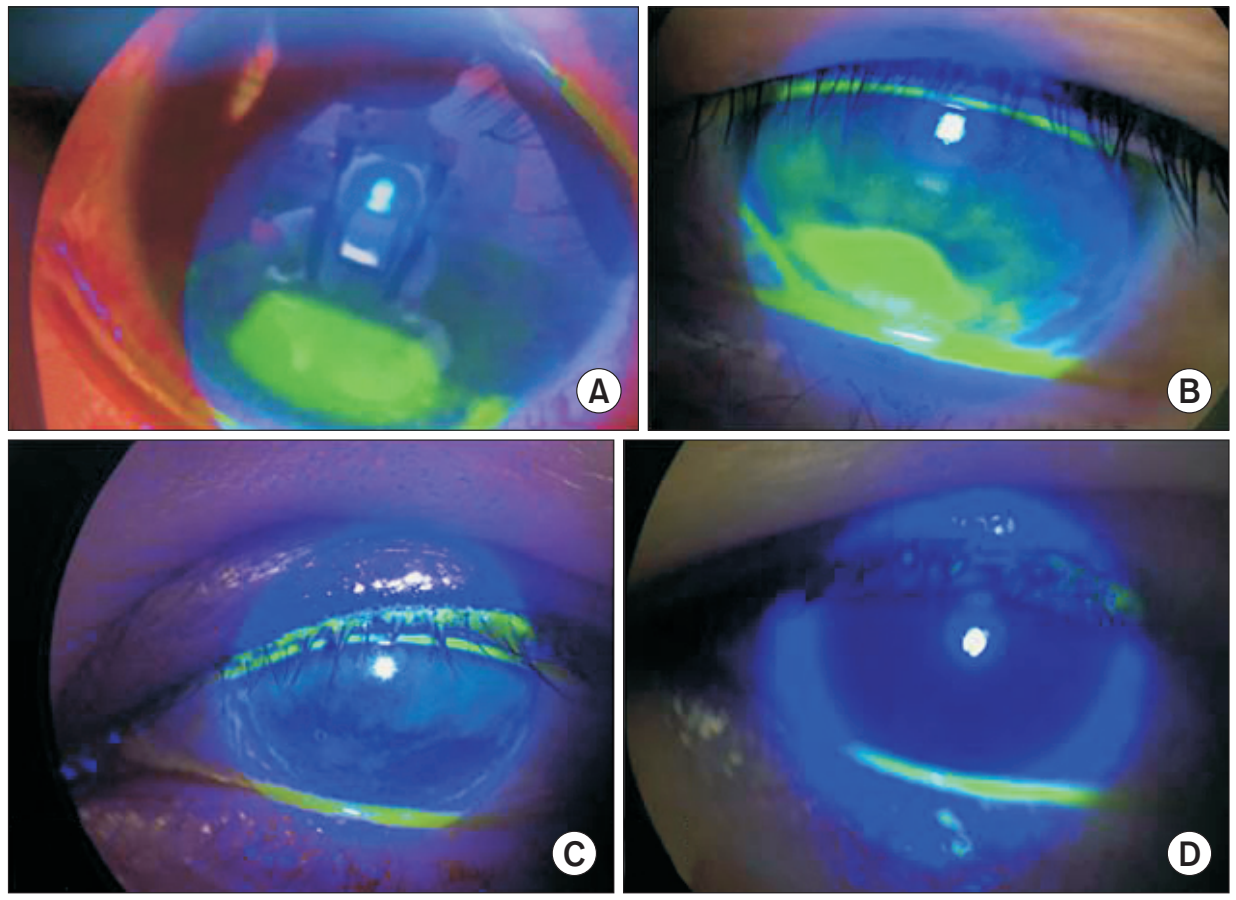

Fig. 3. Right eye (A) and left eye (B) presented with epithelial erosion. A complete epithelial defect resolution was observed after 72 hours in the right eye (C) and left eye (D), with the presence of poor ocular surface on the right eye (C). 
and more easily than acids. Generally, acids are less harmful than alkalis [2]. As EMLA cream is alkaline, it causes alkali burns to the cornea. Conners et al. [3] reported the inflammatory process of alkali burn in rabbit corneal epithelium. The synthesis of arachidonic acid metabolites was increased by 40 fold in the epithelium; these metabolites are particularly active in inflammation and relevant in neovascularization. Brown et al. [4] demonstrated similar findings in albino rabbits.

The exposure of the cornea to EMLA cream can cause injury. As a side effect, local anesthetics mask the pain, discomfort, and injury, which get further exacerbated with no immediate removal of the causative agent. The pharmacological effect of the anesthetic can disrupt the integrity of the corneal epithelium, and subsequent irrigation can further deslough the loosened epithelium.

Similar published reports were reviewed. Bloch et al. [5] reported a similar case in one eye following the use of a local anesthetic. Brahma and Inkster [6] reported two cases of ocular injury following a presumed exposure of EMLA cream; one of the boys who had corneal abrasion had rubbed his eye. Eaglstein [7] reported large corneal abrasions following an erbium laser procedure with the use of EMLA cream after removal of metal eye shield. Another report by Chevaleraud et al. [8] described significant eye damage in patients who had EMLA cream applied under occlusion. Conjunctival injection was reported after the exposure to EMLA cream in a study [9].

\section{Conflicts of interest}

The authors have nothing to disclose.

\section{References}

1. Bisla K, Tanelian DL. Concentration-dependent effects of lidocaine on corneal epithelial wound healing. Invest Ophthalmol Vis Sci 1992;33:3029-33.

2. Murchison A, Trief D, Auran JD, Woodward MA, Syed ZA. Chemical (alkali and acid) injury of the conjunctiva and cornea [Internet]. San Francisco (CA): EyeWiki; c2020 [cited 2020 Mar 1]. Available from: https://eyewiki.aao.org/Chemical_ (Alkali_and_Acid)_Injury_of_the_Conjunctiva_and_Cornea.

3. Conners MS, Urbano F, Vafeas C, Stoltz RA, Dunn MW, Schwartzman ML. Alkali burn-induced synthesis of inflammatory eicosanoids in rabbit corneal epithelium. Invest Ophthalmol Vis Sci 1997;38:1963-71.

4. Brown SI, Wassermann HE, Dunn MW. Alkali burns of the cornea. Arch Ophthalmol 1969;82:91-4.

5. Bloch E, Watt L, Hugkulstone CE. Corneal alkali burn from local anesthetic cream. Cornea 2016;35:e4-5.

6. Brahma AK, Inkster C. Alkaline chemical ocular injury from EMLA cream. Eye (Lond) 1995;9(Pt 5):658-9.

7. Eaglstein NF. Chemical injury to the eye from EMLA cream during erbium laser resurfacing. Dermatol Surg 1999;25:5901.

8. Chevaleraud E, Leroy L, Lebuisson DA. [EMLA cream: prudent use and warnings]. Ann Fr Anesth Reanim 1995;14:459. French.

9. Gotsis SS, Volonaki OM, Theodossiadis GP. Percutaneous anaesthesia with a lignocaine-prilocaine cream (Emla) for eyelid skin surgery. Br J Ophthalmol 1994;78:209-10. 